\title{
Deep Venous Thrombosis (DVT) in Lower Extremity Amputation as Cause of Pulmonary Embolism
}

\author{
Montserrat Pérez Pinar ${ }^{1}$, Regina Pastor Toledo ${ }^{2}$, Antonio Hernandez Castro ${ }^{2}$, Julián Solís García del Pozo $^{1}$ \\ ${ }^{1}$ Internal Medicine Department. Hospital de Villarrobledo, Albacete, Spain \\ ${ }^{2}$ Radiology Department. Hospital de Villarrobledo, Albacete, Spain
}

Received: $23 / 04 / 2015$

Accepted: 08/04/2015

Published: $21 / 05 / 2015$

How to cite this article: Pérez Pinar M, Pastor Toledo R, Hernandez Castro A, Solís García del Pozo J. Deep venous thrombosis (DVT) in lower extremity amputation as cause of pulmonary embolism. EJCRIM 2015;2:doi: 10.12890/2015_000218

Conflicts of Interests: The authors declare that they have no conflicts of interest in this research

This article is licensed under a Commons Attribution Non-Commercial 4.0 License

\section{ABSTRACT}

The authors describe the case of a 43-year-old man with a right-leg knee amputation performed 14 years prior. He presented to hospital with dyspnea. A pulmonary embolism was detected. A Doppler ultrasound test showed deep vein thrombosis (DVT), which affected the stump of the amputated limb. When a pulmonary embolism is detected in a patient with an amputated lower limb, an exploration of the stump should be performed to rule out this uncommon complication.

\section{LEARNING POINTS}

- Deep vein thrombosis (DVT) is a possible complication on limbs that have suffered amputation, even after several years of evolution.

- DVT in a stump can also occur without symptoms or local signs.

- In cases of pulmonary embolism in patients who have suffered a lower limb amputation, the radiologist should also explore the stump by ultrasound to determine the prevalence of venous thrombosis.

\section{KEYWORDS}

Deep vein thrombosis, limb stump, pulmonary embolism

\section{INTRODUCTION}

Deep vein thrombosis (DVT) of an amputated limb stump is a rare pathology. Most studies that have focused on this complication refer to postoperative periods ${ }^{[1,2]}$. Venous thrombosis in patients with longer-term amputation is rare ${ }^{[3]}$. We report the case of a patient with a right-leg knee amputation performed 14 years prior, who suffered a pulmonary embolism. DVT in the right, lower limb stump was diagnosed.

\section{CASE RECORD}

We report the case of a 43-year-old patient who had a traffic accident 25 years earlier. As a result, he suffered a chronic osteomyelitis in the right leg, which required an amputation approximately 14 years prior to his presentation in hospital.

The patient was admitted to hospital with exertional dyspnea. On physical examination, cardiopulmonary auscultation was normal and there were no signs of inflammation or edema in the stump of the patient's right thigh. Among the diagnostic tests performed in the Emergency Room, a high D-dimer of $3820 \mathrm{mcg} / \mathrm{I}$ was found. The chest X-ray was normal. The computed tomography pulmonary angiogram showed filling defects of intravenous contrast in the right pulmonary artery; right upper lobar artery; middle lobar artery; right lower lobar artery; left upper lobar artery; and posterior segmental left upper lobe. No pulmonary nodules, masses, areas of consolidation or pleural effusion were observed. Based on a diagnosis of pulmonary embolism, a Doppler ultrasound of the lower limbs was requested. The results showed that the deep venous system of the left lower extremity was permeable, but there were signs of DVT in both common and superficial femoral veins in the stump of the right lower extremity. An abdomino-pelvic ultrasonography was also performed, which showed permeability of the iliac vessels. No abdominal visceral lesions were found. Also, in laboratory examinations, heterozygous for the G20210A mutation of the prothrombin gene was found. The patient was treated with oral anticoagulation. His progress has been favorable, with the progressive disappearance of respiratory symptoms.

\section{DISCUSSION}

We describe a rare case of DVT in the stump of a lower limb amputation that the patient had suffered 14 years prior. There are few similar such cases reported in medical literature. Baars et al. described the case of a 34-year-old patient who underwent a knee amputation and who 

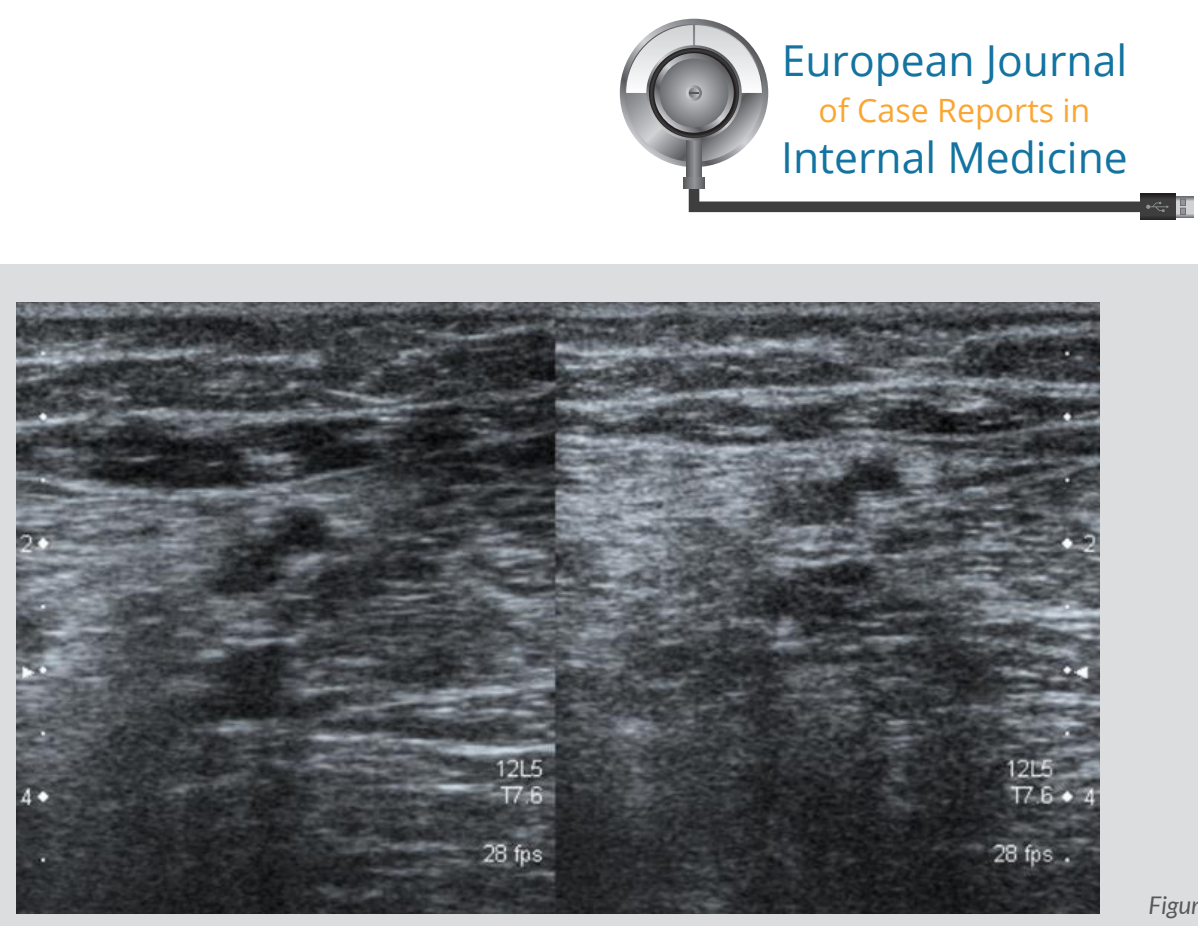

Figure 1: Deep Venous Thrombosis (DVT) in the limb stump.

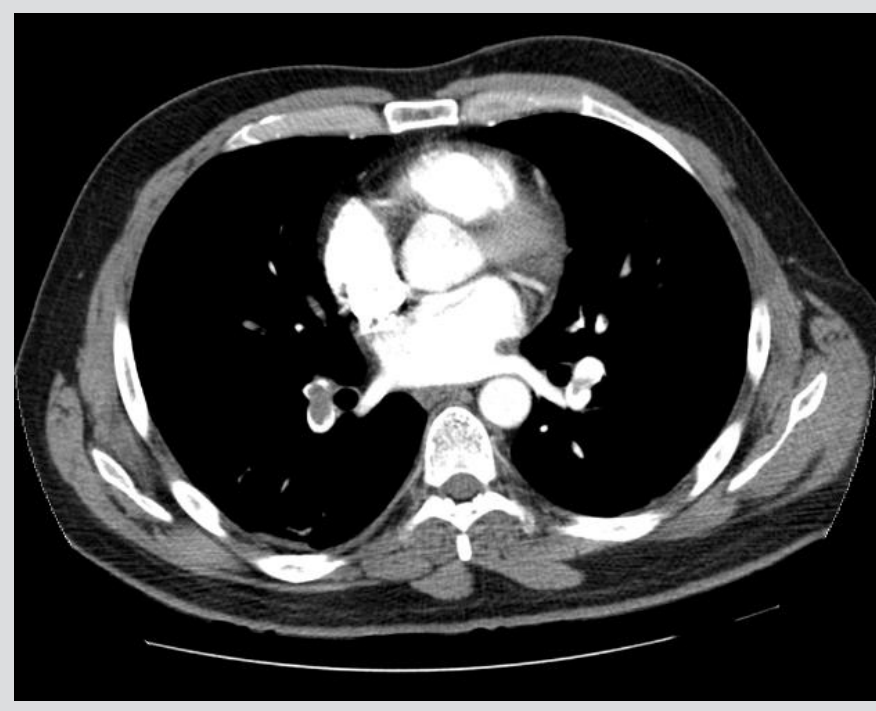

Figure 2: Central filling defects in pulmonary arteries bilaterally, in relation to acute pulmonary embolism.

developed a DVT and pulmonary embolism ${ }^{[4]}$. In this case, the patient had symptoms in the stump, such as redness and swelling. Chong et al. described two patients with swelling of the stump who were treated initially as possible infectious process, however DVT was found to be the cause $^{[5]}$. O'Reilly et al. described a series of 133 amputee patients who were followed over a two-year period ${ }^{[3]}$. This study aimed to assess the utility of high-resolution ultrasound in the diagnosis of causes of pain in the stump. Eighty percent of amputations involved the lower limbs. The most frequent complications were the appearance of neuromas, followed by inflammation, soft-tissue calcifications, and other processes, such as infections or skin lesions. Venous thrombosis was among the less frequent lesions detected.

The case described here is interesting for two reasons. Firstly, the patient underwent an amputation 14 years prior to the current episode, without having diagnosed previous complications of the stump. Secondly, the stump showed no sign of disease, and thrombosis was diagnosed from the patient's dyspnea, which was caused by a pulmonary embolism. The case shows the importance of exploring properly the stump of an amputated limb, through the use of a Doppler ultrasound test, to determine the prevalence of DVT as a cause of pulmonary embolism.

\section{REFERENCES}

1. Matielo MF, Presti C, Casella IB, Netto BM, Puech-Leão P. Incidence of ipsilateral postoperative deep venous thrombosis in the amputated lower extremity of patients with peripheral obstructive arterial disease. J Vasc Surg. 2008;48:1514-9.

2. Bandeira FC, Pitta GB, Castro AA, Miranda F Jr. Postoperative incidence of deep vein thrombosis after major lower extremity amputation. Int Angiol. 2008;27:489-93.

3. O'Reilly MA, O'Reilly PM, O'Reilly HM, Sullivan J, Sheahan J. High-resolution ultrasound findings in the symptomatic residual limbs of amputees. Mil Med. 2013;178:1291-7.

4. Baars EC, Ettema HB, Fritschy WM. [Deep venous thrombosis in an amputation stump]. Ned Tijdschr Geneeskd. 2007;151:2061-3.

5. Chong DK, Panju A. Deep venous thrombosis as a cause of stump swelling in two lower extremity amputee patients. Arch Phys Med Rehabil. 1993;74:1002-3. 